\title{
The New Americans?
}

\section{The Sino-African Relationship on Chinese and Ethiopian}

\section{Screens}

SPECIAL COLLECTION:

THE ASIAN-AFRICAN

FILM CONNECTION

\section{RESEARCH}

MICHAEL W. THOMAS (D)

CHRIS BERRY (1)

*Author affiliations can be found in the back matter of this article
(1) 1

Open Library of Humanities

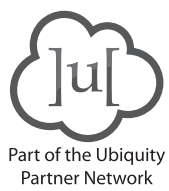

\begin{abstract}
China has forged substantial political and economic relations across Africa since the turn of the new millennium. This essay scrutinises the cultural representations of these relations from the perspectives of popular, locally produced cinemas in both the Chinese and Ethiopian contexts. We argue that cultural readings of the power relations between China and Africa help to nuance the often-over-simplified narratives that posit China as the new America. While Chinese action films set in indistinct African locations can be seen to replace the Hollywood 'white saviour' with a 'Chinese saviour', American characters and/or institutions are commonly portrayed as morally corrupt in both Amharic and Chinese cinema. We explore how representations of 'Chinese saviours' are imagined in opposition to American antagonists and how emerging African commercial cinemas, such as in Ethiopia, portray local characters reclaiming their own agency. The analysis of Ethiopian films identifies that suspicion and caution are overriding emotions when Ethiopian characters deal with outsiders, with action heroes/heroines far less 'gung ho' than their interventionist Chinese or American counterparts. It is these African representations of African characters as heroes and not victims, and who play foreign actors at their own game, that reveal more complex interpretations of Sino-African relations.
\end{abstract}

CORRESPONDING AUTHOR: Michael W. Thomas

SOAS, GB

mt97@soas.ac.uk

\section{KEYWORDS:}

Chinese cinema; Ethiopian cinema; African-Chinese screen representations; representations of otherness; popular culture in China; popular culture in Ethiopia

TO CITE THIS ARTICLE: Thomas, MW and Berry, C. 2021. The New Americans? The Sino-African Relationship on Chinese and Ethiopian Screens. Open Screens, 4(1): 3, pp. 1-7. DOI: https://doi. org/10.16995/os.39 
In 2009, the People's Republic of China (PRC) became Africa's largest trading partner. The country it took over from was the United States of America (USA). The Eurasian Times reported that between 2000 and 2014 the annual volume of Sino-African trade grew from US\$10 billion to US\$220 billion (2017). The article draws its data from the work of the Johns Hopkins University China Africa Research Initiative (CARI). Reading through CARI's website, (http://www.sais-cari.org/) indicates that the collapse of commodity prices has brought the value of trade down since then, but that China remains by far the continent's biggest trading partner. This shift is one of many that has led people to consider the possibility that, if the last century was America's, this one will be China's (Fenby 2014). What would it mean to suggest that the Chinese are the new Americans in Africa? Trade data is one way to answer that question, but it does not explore how the change is perceived, either in Africa or in China. Public opinion surveys generate knowledge about what people are willing to tell a pollster. But cinema, and especially successful commercial films that can be said to have 'touched a nerve' provide another window.

In this short essay, we look at how Africa appears in Chinese cinema and vice versa. Recently, two films about or set in Africa have been blockbuster hits in China. In Africa, the prominence of China within contemporary Africa is nowhere more evident, perhaps, than in Ethiopia. In the past twenty years, ruled by the Ethiopian People's Revolutionary Democratic Front (EPRDF) until its dissolution in 2019, the country's developmental aspirations and governing strategies have closely emulated the Chinese model (Thakur 2009). Therefore, we look at the roles played by foreigners in contemporary Amharic cinema from Ethiopia. In both cases, we do find plenty of evidence for a China-takes-over-from-America narrative. The Chinese films appropriate Hollywood blockbusters and repopulate them with Chinese heroes. In the Amharic films, Chinese characters are increasingly common in foreigner roles. However, we also find that both the Chinese and Amharic films implicitly and explicitly criticize Americans and Westerners in general. Therefore, they manifest both the West's loss of ethical credibility and a hope that the Chinese century might be different. However, it must be acknowledged that the hope expressed by the films fits the censorship requirements of both regimes, and it is impossible to know how much of a role the hopeful vision for a new Sino-African future played in the popularity of the films.

\section{AFRICA IN CONTEMPORARY CHINESE CINEMA}

Although Chinese media coverage and television programming has featured recent Chinese activity on the continent (Puppin 2017), Africa was largely absent from Chinese cinema screens. Even if filmmakers wanted to go there, budget limitations made it impossible. All that changed recently with the explosive growth of the industry and production budgets, and with the release of Zhanlang 2/Wolf Warrior 2 (Wu Jing, 2017), followed within months by Honghai Xingdong/Operation Red Sea (Dante Lam, 2018). Although neither film was an export success, each topped the annual Chinese box office, earning hundreds of millions of dollars (Box Office Mojo 2020).

Both films have evoked comparisons with Hollywood movies. Their plots consist of missions to rescue Chinese citizens caught up in African civil wars. Wolf Warrior 2's protagonist is Leng Feng (literally, 'Cold Front'), a former special operations soldier whose angry desire for justice leads to his discharge from the military, just like the eponymous protagonist of Rambo: First Blood (Ted Kotcheff, 1972) and its various sequels. If Leng Feng is a maverick, Operation Red Sea is all about discipline, teamwork, and camaraderie among an 8-person assault squad operating off a navy ship with helicopters-a bit like Top Gun (Tony Scott, 1986).

This lineage shows that China-taking-over-fromAmerica extends to film production, too. The Chinese film industry has long shifted from trying to shut Hollywood out of its domestic market to letting it in, but at the same time learning from Hollywood to compete with it in a paradoxical process of resistance through strategic submission (Berry and Farquhar 2006: 207-9). Since Rambo and Top Gun, America has begun to lose faith in heroic military adventure, as indicated by films like Black Hawk Down (Ridley Scott, 2001), about the disastrous intervention in Mogadishu, Somalia in 1993. Wolf Warrior 2 and Operation Red Sea's huge success may indicate a Chinese cultural appetite to continue that more optimistic vision of global action adventure.

The contrasting protagonists of Wolf Warrior 2 and Operation Red Sea make them seem very different at first, but closer inspection reveals many similarities. Indeed, Operation Red Sea also has its Chinese maverick figure in the form of a woman journalist called Xia who is a French citizen working with an independent news outfit based in Casablanca. And Wolf Warrior 2 has its Chinese fleet with disciplined troops offshore, eventually intervening to help Leng Feng towards the end of the film. In other words, the overall narrative may be quite similar, but one is focalized through the maverick individual, the other through the disciplined squad.

Wolf Warrior 2 and Operation Red Sea's shared qualities extend to their vision of Africa. Both start with rescues of Chinese ships invaded by pirates. The title informs us this is happening 'off the coast of Madagascar' in Wolf Warrior 2 and 'off the Somali coast' in Operation Red Sea. This impression of Africa as lawless and disordered, or what the Chinese call 'luan' (chaotic), continues when the films move onshore. In both cases, terrorists attack 
the local government and civil war necessitates the rescue of Chinese citizens. Wolf Warrior 2 even features a secondary plot about an Ebola-like illness called Lamanla.

The precise settings of both films are hazy. Each is thought to have been inspired by real incidents. In 2011, when Chinese citizens had to be rescued during the Libyan civil war, the Chinese government struggled to get help over in time (Plarrell-Plesner and Duchâtel 2014). Wolf Warrior 2 shows a locally-based Chinese citizen rescuing people when the United Nations rules prevent the Chinese navy from intervening, as though providing a wished-for corrective narrative. When similar problems emerged in Yemen in 2015, the Chinese navy proudly rescued both its own and foreign citizens (Rajagopalan and Blanchard 2015), providing the model for Operation Red Sea.

However, both films adopt fictional settings. Wolf Warrior 2 used South Africa for locations but does not invent a country, instead using a title to locate the first scene after the rescue in the fictional port city of 'Shenmatasawa Bay, Africa', homogenising the continent, as also discussed by Deanna Hardy, Jennifer Coates and Jamie Coates in their article in this issue. Operation Red Sea is even vaguer. Although location scenes in Operation Red Sea were shot in Morocco, the country the film is set in is called Yewaire, which is presumably somewhere close to 'off the Somali coast'. Indeed, if Yewaire is supposed to be Yemen, then the film may not even be set in Africa.

The difficulty of determining which continent Operation Red Sea takes place on is compounded by the lack of significant local characters. Yewaire is little more than a stage for the assault squad's operations, with a cast of citizen-victims and brutal terrorists. However, when those terrorists talk, it is in Arabic, and their local leader is a man called Sayyed, who dresses in black robes and a turban, echoing the media image of IS leader Abu Bakr Al-Baghdadi. The film could be taking place anywhere in the Arabic-speaking world from Morocco to Iraq.

Wolf Warrior 2 has the same 'Arab terrorist' stereotypes as Operation Red Sea (and the Hollywood movies they might be taking over from). But it also has secondary African characters with dialogue. The most significant are Leng Feng's teenage 'godson' Tundu and his mother, who is working inland in a Chinese-owned factory. Cheerful and chubby, she perpetuates the same stereotype that provoked criticism when rendered in blackface on China Central Television's New Year Gala show in 2018 (Perlez 2018).

However, if we accept that both films represent Africa and China's relation to it, the most interesting tension running through them is between a purely instrumental relationship and deeper engagement. This is expressed in the contrast between the Chinese military, safely off the coast on their ships and just following orders, and the characters of Leng Feng in Wolf Warrior 2 and the journalist
Xia in Operation Red Sea. Three years after dealing with the pirates off Madagascar, Leng Feng reappears as a trader of Chinese goods and a popular figure amongst the locals. When the factory where Tundu's mother works comes under attack, personal connections to Tundu and his mother are as strong a motivation for Leng Feng's mission as saving Chinese citizens.

In Operation Red Sea, the assault squad's mission is to rescue one Chinese citizen, Deng Mei, who is being held hostage. The French citizen but ethnic Chinese journalist Xia has her sidekick, too - an assistant called Abu, who is captured and beheaded by the terrorists. It is at this point that Xia reveals to the squad leader that her husband and daughter were killed in the 2005 London bus bombing. She then laments that she could not even protect Abu, a train of thought that indicates he has taken their place in her mind. It is this revelation that leads the squad leader to expand his rescue mission to as many of the hostages as possible, and not just the Chinese citizens.

A similar moment occurs in Wolf Warrior 2, when Leng Feng finally gets to the Chinese-owned factory. The factory manager declares that only Chinese workers will be rescued, but Leng Feng, looking at Tundu's mother, contradicts him, insisting that everyone will be rescued. These scenes not only show feelings (ganqing, in Chinese) overcoming objective and rational rules. They also indicate an ideological overdetermination reminiscent of the thinking that validated colonialism. In both films, local men are either absent, ineffectual, or terrorists. Local women and children must be rescued by Chinese men (and one or two token Chinese women). Has the 'white saviour' become the Chinese saviour in these films? Has Africa become the 'Chinese man's burden' (Xiang 2018)?

However, China-taking-over-from-America as a neo-colonial power is complicated in both films by the role of white men as villains. While Chinese business and other activities in Africa are very visible, almost no other foreign involvement can be seen. The significant exception to this pattern is the villain. In Wolf Warrior 2, the most important opponent faced by Leng Feng is Big Daddy, a white European-looking and North Americanaccented mercenary fighter employed by the terrorists. Much as in Bruce Lee films (Berry and Farquhar 2006: 203), Leng Feng takes on a racial hierarchy of opponents, culminating in his duel with Big Daddy. In Operation Red Sea, the stakes are ramped up when it is discovered that the white European-looking and North Americanaccented head of Greenville Energy, the company that Deng Mei works for, is not only collaborating with the terrorists but also planning to supply them with uranium to make a 'dirty bomb'. In other words, in both films, the only serious competitors for power on the African continent are American.

Also in both cases, the films are careful to distance these figures from the government of the United States, 
presumably because the Chinese censors are unwilling to go quite that far. But what this effort to contrast the good Chinese with the bad white guys also does is raise China's pre-market economy history. The country's previous major involvement with Africa was during the Mao era, when the aid that China gave to countries like Ghana, Zambia and Tanzania were presented as part of a Third World internationalist revolution (Strauss 2009). In those days, China promoted itself as a socialist alternative to the West. Today, it is still socialist, but also part of the market economy. However, in these films, America is implied to be purely cynical in its role on the continent, whereas the hope for a more ethical role is raised for China, and this optimistic flattery may have appealed to its Chinese audiences.

\section{CHINESE IN CONTEMPORARY AMHARIC CINEMA}

Representations of Chinese involvement in Africa compared with other foreigners in commercial films made in Amharic in Ethiopia also complicate the linear notion of China-taking-over-from-America. Beyond the political and economic headlines there is an increasing presence of Chinese nationals within African countries. In 2016, La Yifan, the Chinese Ambassador to Ethiopia and the African Union (based in Addis Ababa), estimated 60,000 Chinese nationals were working in Ethiopia and purportedly responsible for the employment of one million Ethiopians (The Newsroom, 2016). These Chinese nationals are most visible as train drivers on Addis Ababa's Light Railway or as the foremen in Chineserun factories and construction projects, from building railways and roads to industrial parks, stadiums and the new African Union headquarters (a gift from the Chinese government). These everyday workplace encounters between Ethiopian labourers and Chinese foremen have given rise to nuanced debates about the impact of Chinese investment in Ethiopia. China's 'business is business' approach is reflected in them and distinguishes the Chinese presence in Ethiopia as alternative to the international expatriate community of aid workers, whose work is often subject to certain legal, economic or political conditions.

The rising profile of Chinese people in Ethiopia is also manifested in the common use of the term 'China' by Ethiopians as a catch-all phrase used to identify not only any Southeast or East Asian but also white Europeanlooking foreigners. This anecdotal evidence points to the far reaching impacts an increased Chinese presence in Ethiopia is having on Ethiopian society and culture. Crucially for this article, it also shows how the Chinese foreigner or 'China' has overtaken the 'Ferenj' ('white European-looking foreigner') as the generic marker denoting the foreign 'other'.
The Amharic film industry in Ethiopia is relatively recent, becoming commercially viable late in 2002, so it is not possible to speak of long-term changes in representation. This period is also one dominated by the EPRDF's rule and warming relations with China. Ethiopian stereotypes of the Chinese abound, as do stereotypes of any other identifiable community in the country. But the generally positive representations of Chinese characters in the commercial Amharic film industry in Ethiopia present interesting comparisons to the more mixed and often negative representations of Euro-American and diaspora characters. In terms of the representation of foreigners in Amharic films, then, there has not so much been a discernible shift but instead a sustained distinction between these three major and most distinct groupings based on racial appearance.

Members of the Ethiopian diaspora from America are the most commonly represented group of foreigners. The characters typically look Ethiopian but sound and behave like American foreigners. Films such as Abay vs Vegas/Blue Nile vs Vegas (Tewodros Teshome, 2010) and Ayrak/Don't Be Distant (Fikreyesus Dinberu, 2014) present members of the Ethiopian diaspora as being morally bankrupted by their material wealth in opposition to morally superior Ethiopian-based characters seen as integrated within Ethiopian society, religion and traditions. The diaspora character, then, represents an Ethiopian 'other' with different mannerisms and the inability to communicate in Amharic or other Ethiopian languages. They often speak in the most vulgar and clichéd American accent, a symptom of their intellectual deficit with regards to Ethiopia. The road to redemption, however, often remains open to these characters as their physical appearance and genetic makeup ultimately offer them the option to relocate to Ethiopia and (re)integrate within Ethiopian society. Those Ethiopian diaspora characters who do so are usually women who fall in love with local Ethiopian men, such as in Yefiker ABCD/Love's ABCD (Dawit Negash, 2012), Tikur Engida/Black Stranger (Mikael Tamrat, 2014) and Amen (Aziz Mohammed, 2012). Ethiopian diaspora characters are by their very association with America commonly represented as being enticed into a pursuit of wealth instead of moral/spiritual enlightenment. These characters may then be further agents of corruption and villainy within Ethiopia or may instead recover their lost soul in the land of their ancestors. Such representations of America as a corrupting cultural force have long held sway in Ethiopia and many other African nations.

The representations of Chinese characters in Amharic films both criticise and reassert local Ethiopian stereotypes. These representations, however, paint a more nuanced portrayal of Chinese involvement in Ethiopia, as has been previously written about by Jedlowski and Thomas (2017) with regards to the popular comedies Made in China (Mesfin Haile-Eyesus and Tewodros Seyoum, 2012) and Zeraff (Naod Gashaw, 2011). 


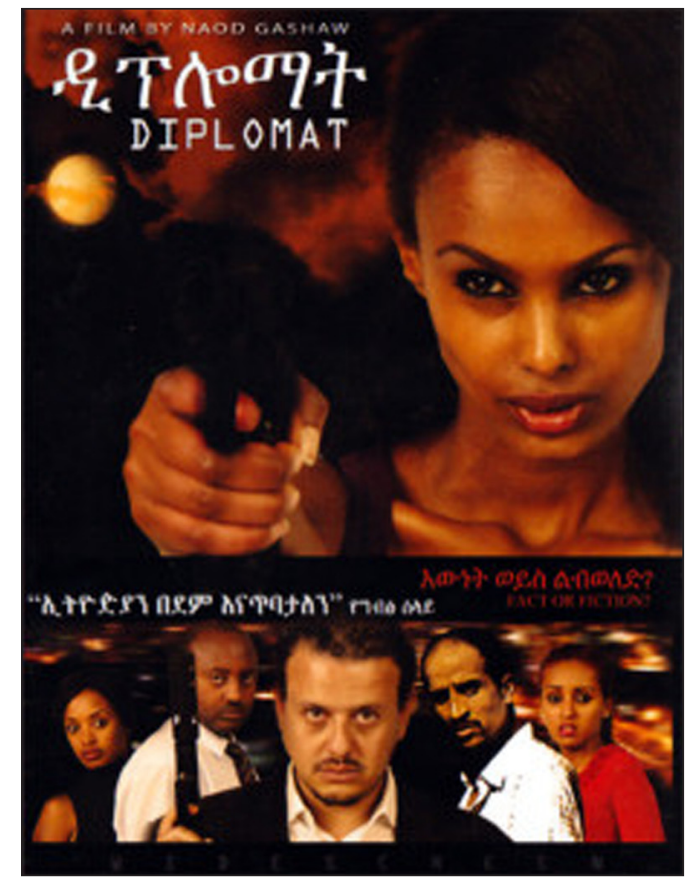

Figure $1 \mathrm{~A}$ poster for Diplomat.

Of particular interest here, for its specific sociogeopolitical overtures, is the thriller Diplomat (Naod Gashaw, 2012) (Figure 1). Unlike Wolf Warrior 2 and Operation Red Sea that steer clear of implicating foreign governments in their chaotic fictional worlds, Diplomat explicitly portrays and identifies foreign governments as partaking in clandestine operations within Ethiopia. Diplomat follows the multitalented Ethiopian antiterrorist police commander, Kidist Temesgen, as she leads an operation that uncovers and ultimately thwarts a joint American CIA and Egyptian plot to assassinate the Sudanese President on Ethiopian soil. The film specifically references the dispute Egypt has with Ethiopia over the building of the Grand Ethiopian Renaissance Dam on the Blue Nile, even prophetically foreshadowing talks held by Egyptian officials to sabotage the dam in 2013 (Maasho 2013). The CIA, however, is the main actor in this plot to kill the Sudanese President in an intricate plan to frame Ethiopia, cause a dispute between Ethiopia and Sudan and then enable American peace-keeping and nationbuilding missions. The Ethiopians are only able to foil the plot with the help of the Chinese who identify the CIA operative and help disarm a bomb specifically timed and placed to kill the Sudanese President after he lands in Addis Ababa.

The pivotal scene in Diplomat presents the Ethiopians with two options of who to trust to disarm the bomb. Out of the two nuclear engineers in the country, one American ambassador and one Chinese security ambassador, Kidist makes the decision to go with Engineer Li from China. Kidist explains that he can be trusted because they have worked together previously in the Eastern Ogaden (Somali) region of Ethiopia, referring to the 2007 Abole raid where nine Chinese workers and 65 Ethiopians lost their lives at the hands of Ogaden National Liberation Front (ONLF) rebels (Tadesse and Heavens 2007). The film then depicts the close relationship between Kidist and Engineer Li as they converse partly in Mandarin and partly in Amharic. Li quickly identifies that the bomb is not nuclear but still has a blast radius of three kilometres. He notifies Kidist that the Chinese government also wants to question the CIA agent they are after. As Li manages to disarm the bomb, Kidist traces down the CIA agent and approaches him just as he expects the bomb to go off. But Kidist knows diplomatic immunity means she cannot arrest the American, played by a half Ethiopian American actor who speaks fluent Amharic. Instead, she speaks Mandarin on her phone, tricking the American into thinking she is calling in the Chinese. This provokes the American to draw his gun, only for Kidist to shoot him first in an act of self-defence.

As with Wolf Warrior 2 and Operation Red Sea, in Diplomat it is also the Americans who are the villains, manipulating African politics and attempting to destabilise the region for their own benefit. The position of America and Egypt in the film does correspond to the reality of Ethiopia's geopolitical relations but it is striking how explicit the negative portrayal of an American government institution is, particularly as strict censorship controls were in place at the time. The role played by Engineer Li, alternatively, is only a cameo. Just like the working relationship between China and Ethiopia that both nations champion, he takes his leave as soon as his job is completed.

The expertise and usefulness of the Chinese character in Diplomat is undeniable, nevertheless, the role the Chinese play does not go unquestioned. Li's entrance is accompanied by a remark from the head of the Ethiopian Anti-Terrorist Police suspecting that the Chinese will torture the CIA agent if they manage to catch him. It is not surprising to see a film that uses positive and negative stereotypes of other nations in order to better define its own nation's standing as a regional power in its own right while also blaming its internal problems on foreign agents. The successful navigation by Ethiopian agents of Chinese, American and Egyptian players crucially depicts China as a viable alternative to American aid. But above all else, it advocates the independent capabilities of resourceful Ethiopians in the face of impending international crises.

\section{CONCLUSION}

In both Amharic and Chinese films, we see Chinese characters appearing amongst the most prominent foreigners on the African continent. In Chinese films, the plots, the roles of their protagonists, and the stereotypical representations of Africans are all reminiscent of those found in earlier Hollywood films. But simultaneously, the 
films critique Americans, expressing the hope that, if they are indeed the new Americans, they will be better than the old ones. Amharic films seem to share this aspiration for the new century. Americans appear either directly as villainous figures scheming behind the scenes, or American culture appears as the force that has corrupted diasporic Ethiopians. Chinese characters are arguably the generic foreigners today, but they are also the repositories for a hope of a better deal for Africans, offering a more equal partnership that, perhaps, Americans once inspired too.

However, some notes of caution must be sounded. First, censorship has prevailed in both Ethiopia and China. In these circumstances, there are limits to what the popularity of the films can tell us about how strongly they resonate with the responses of locals in both countries to the new African-Chinese relationship. In the absence of strict censorship, particularly after reported government reform in Ethiopia since October 2018 (Astatike 2018), might more critical depictions of Chinese appear in Amharic cinema and should this ever happen in China, of China's role in Africa? Furthermore, as expanded upon by Lindiwe Dovey and Kate Taylor-Jones in their introduction to this collection, what are the appropriate conceptual frameworks for considering the depictions discussed here? In this short essay, we have not engaged deeply with this issue, but we have used terms like the 'other'. Is it appropriate to use terminology that implies a Saidian framework, developed to analyse Europe's relationship to what it called the 'Orient', in the context of how China imagines Africa or how Ethiopians imagine the Chinese in their midst? Is that also part of what 'becoming new Americans' means? If the new Sino-African relationship is structured by power imbalances as great as the old Sino-American one, how much faith can we put in the new and more ethical visions articulated in these films? Alternatively, if we want to look to models other than Orientalism, what local conceptual frameworks, including historic ones, also shape this imagination? These and other questions, such as whether there are differences between cinematic representations and those found in other media, or how other African cinemas represent the Chinese, await further research.

\section{COMPETING INTERESTS}

The authors have no competing interests to declare.

\section{AUTHOR AFFILIATIONS}

Michael W. Thomas (D) orcid.org/0000-0001-7955-3641

SOAS, GB

Chris Berry (D) orcid.org/0000-0002-5752-3107

Kings College London, GB

\section{REFERENCES}

Astatike, D. 2018. Censorship Over for Theatres, Film: Producers Rejoice. Addis Fortune, 6 October 2018 [online access at $h$ ttps://addisfortune.net/articles/censorship-over-fortheaters-films-producers-rejoice/ last accessed 9 April 2019].

Berry, C and Farquhar, M. 2006. China on Screen: Cinema and Nation. New York: Columbia University Press.

Box Office Mojo. 2020. Chinese Yearly Box Office. IMbpro 2 July 2020 [online access at https://www.boxofficemojo.com/ year/?area=CN last access 2 July 2020].

Fenby, J. 2014. Will China Dominate the $21^{\text {st }}$ Century? London: Polity.

Jedlowski, A and Thomas, M. 2017. Representing 'Otherness' in African Popular Media: Chinese Characters in Ethiopian Video-Films. Journal of African Cultural Studies, 29(1): 63-80. DOI: https://doi.org/10.1080/13696815.2016.1241704

Maasho, A. 2013. Ethiopia Says it Won't Bow to Egyptian Pressure on Dam. Reuters, 7 June 2013 [online access at https://www.reuters.com/article/us-ethiopia-egypt-nile/ ethiopia-says-it-wont-bow-to-egyptian-pressure-over-niledam-idUSBRE95616E20130607 last accessed 9 April 2019].

Perlez, J. 2018. With Blackface and Monkey Suit, Chinese Gala on Africa Causes Uproar. The New York Times, 16 February 2018 [online access at https://www.nytimes. com/2018/02/16/world/asia/china-africa-blackface-lunarnew-year.html last accessed 6 April 2019].

Plarell-Plesner, J and Duchâtel, M. 2014. International Rescue: Beijing's Mass Evacuation from Libya. Adelphi Series 54(451): 107-124. DOI: https://doi.org/10.1080/10670564. 2014.898900

Puppin, G. 2017. Making Space for Emotions: Exploring ChinaAfrica 'Mediated Relationships' through CCTV-9's African Chronicles (Feizhou jishi). Journal of African Cultural Studies, 29(1): 131-174. DOI: https://doi.org/10.1080/13696815.20 16.1268952

Rajagopalan, M and Blanchard, B. 2015. China Evacuates Foreign Nationals from Yemen in Unprecedented Move. Reuters, 3 April 2015 [online access at www. reuters.com/article/us-yemen-security-china/ china-evacuates-foreign-nationals-from-yemen-inunprecedented-move-idUSKBNOMU09M20150403 last accessed 22 March 2019].

Strauss, J. 2009. The Past in the Present: Historical and Rhetorical Lineages in China's Relations with Africa. The China Quarterly, 199: 777-795. DOI: https://doi. org/10.1017/S0305741009990208

Tadesse, T and Heavens, A. 2007. Rebels Kill 74 in Ethiopian Oil Field Raid. Reuters, 24 April 2007 [online access at https://uk.reuters.com/article/uk-ethiopia-china/rebels-kill74-in-ethiopia-oil-field-raid-idUKL246401020070424 last accessed 9 April 2019].

Thakur, M. 2009. Building on Progress? Chinese Engagement in Ethiopia. South African Institute of International Affairs Occasional Paper, 38: 4-23. 
The EurAsian Times. 2017. China Africa Trade: Chinese Have Replaced Britishers as Our Masters! 21 December 2017 [online access at https://eurasiantimes.com/china-africatrade-relations/ last accessed 5 April 2019].

The Newsroom. 2016. China Empowers a Million Ethiopians: Ambassador. eNCA, 26 January 2016 [online access at https://www.enca.com/money/china- empowers-million-ethiopians-ambassador last accessed 9 April 2019].

Xiang, Z. 2018. Toxic Masculinity with Chinese Characteristics. MCLC Resource Center, 22 February 2018. [Available at http://u.osu.edu/mclc/2018/02/22/wolf-warrior-ii-the-riseof-china-and-gendersexuality-politics/ [Last accessed 23 March 2019].

TO CITE THIS ARTICLE:

Thomas, MW and Berry, C. 2021. The New Americans? The Sino-African Relationship on Chinese and Ethiopian Screens. Open Screens, 4(1): 3, pp. 1-7. DOI: https://doi.org/10.16995/os.39

Submitted: 16 July $2020 \quad$ Accepted: 26 February $2021 \quad$ Published: 01 June 2021

COPYRIGHT:

(c) 2021 The Author(s). This is an open-access article distributed under the terms of the Creative Commons Attribution 4.0 International License (CC-BY 4.0), which permits unrestricted use, distribution, and reproduction in any medium, provided the original author and source are credited. See $h$ ttp://creativecommons.org/licenses/by/4.0/.

Open Screens is a peer-reviewed open access journal published by Open Library of Humanities. 